\title{
La modernización del estatuto del animal en la legislación civil española
}

\author{
Nuria Menéndez de Llano Rodríguez \\ Doctoranda del Departamento de Derecho Público de la Universidad de Oviedo \\ Abogada y Miembro de la Comisión de Derecho Animal del Colegio de Abogados de \\ Oviedo \\ Directora del Observatorio Justicia y Defensa Animal \\ Associate Fellow del Oxford Centre for Animal Ethics
}

Recepción: Abril 2018

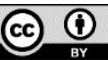

Aceptación: Junio 2018

Este trabajo forma parte del Proyecto de investigación MINECO DER2015-69314-P «Estatuto jurídico de los animales: origen, desarrollo y políticas» (2015-2019)

This work forms part of the MINECO investigation Project DER2015-69314-P «Legal status of animals: origin, development and policies» (2015-2019)

\section{Resumen}

Este trabajo se ha insertado en el Informe sobre la reforma del Estatuto Jurídico Civil de los animales en España, entregado en el Congreso de los Diputados durante la preparación de la Proposición de Ley de reforma del Código Civil, Ley Hipotecaria y Ley de Enjuiciamiento Civil sobre el régimen jurídico de los animales, actualmente en tramitación. En él se ha analizado cómo la regulación de los animales en el Código Civil español necesitaba una revisión urgente para cambiar el paradigma legal de los animales para que dejen de ser considerados meros objetos en propiedad y pasen a ser reconocidos como seres vivos dotados de sensibilidad.

Palabras clave: código civil, estatuto jurídico de los animales, sentiencia, ser sintiente, derecho animal

\section{Abstract. Modernizing the Legal Status of Animals in Spanish Civil Law}

This text is a part of the Report to the changing of the civil law status of animals in Spain, which was submitted to the Spanish Congress of Deputies during the drafting of the ongoing Bill to amend the Civil Code regarding the legal status of animals. It has analyzed how the regulation of animals in the Spanish Civil Code needed an urgent legal review to change the legal paradigm of animals to stop being considered as mere objects in property and becoming to be legally recognized as sentient beings.

Keywords: civil code, legal status of animals, sentience, sentient being, animal law 


\section{SUMARIO}

1. Antecedentes

2. Los animales en el Código Civil de 1889

3. Problemas prácticos y necesidad de la actualización

\section{ANTECEDENTES}

Históricamente el ser humano se ha relacionado con el resto de animales no humanos en términos de aprovechamiento y de ahí que se haya petrificado hasta nuestros días, en el Código Civil español, el estatuto del animal como cosa-recurso ${ }^{1}$.

No obstante, la sociedad española decimonónica, eminentemente agrícola y rural ${ }^{2}$, poco tiene que ver con la sociedad actual en su consideración ética y social de la relación entre los seres humanos y los animales. En las sociedades occidentales actuales, incluida la nuestra, el respeto a los animales constituye un sustrato común ampliamente asentado ${ }^{3}$, que se traduce en el creciente desarrollo legislativo del Derecho Animal ${ }^{4}$ producido en diversos sectores de nuestro ordenamiento. No en vano millones de españoles conviven con animales ${ }^{5}$ a los que consideran un miembro más de la familia, y el sector de los animales de compañía es un pilar económico relevante ${ }^{6}$ que ha ido aumentando exponencialmente con el tiempo y cuya magnitud sirve para ilustrar el apego y la relevancia que tienen los animales de compañía para las familias españolas.

No puede obviarse el hecho de que el Derecho debe ser un reflejo de la sociedad en la que tiene que ser aplicado y en el concreto campo del estatuto jurídico civil de los animales hay un claro desajuste entre éste y el sentir social mayoritario ${ }^{7}$. Además, se ha de reconocer

${ }^{1}$ Cf. GIMENEZ-CANDELA, T., “La descosificación de los animales”, Revista Eletrônica do Curso de Direito da UFSM, v. 12, n. 1 / 2017 p. 298-313 www.ufsm.br/revistadireito

${ }^{2}$ En la España de 1860 el 77’7\% de la población era campesina. Vid. PRIETO, P., Economía y Sociedad en el siglo XIX, p. 23.

${ }^{3}$ La preocupación de los españoles por el bienestar animal como un asunto muy relevante queda patente en el Eurobarómetro 2016 sobre la posición de los europeos hacia el bienestar animal http://ec.europa.eu/commfrontoffice/publicopinion/index.cfm/ResultDoc/download/DocumentKy/71348

${ }^{4}$ MENÉNDEZ DE LLANO, N., “Qué es el Derecho Animal”, Law\&Trends, 23 noviembre 2016. http://www.lawandtrends.com/noticias/derecho/que-es-el-derecho-animal.html

${ }^{5}$ Según los datos contenidos en el censo difundido por la Asociación Madrileña de Veterinarios de Animales de Compañía (AMVAC) con cifras actualizadas a 2015, en España habría más de 20 millones de animales de compañía y según la Asociación del Sector de Animales de Compañía (ASAC), en estos momentos existen en España unas 6.000 clínicas veterinarias y cerca de 5.000 tiendas especializadas. Ver más en: http://www.20minutos.es/noticia/2986945/0/20-millones-mascotas-espanaveterinarios/\#xtor=AD-15\&xts=467263

No obstante la cuantificación no resulta fácil, tal y como pone de manifiesto el Informe sobre el Análisis y la caracterización del sector de los animales de compañía 2015, elaborado por el Ministerio de Agricultura, Alimentación y Medio Ambiente del Gobierno de España, que no han podido completar el estudio al no recibir los datos de los animales registrados en 6 de las 17 CCAA.

http://www.mapama.gob.es/es/ganaderia/temas/produccion-y-mercadosganaderos/20160222 informeestudioparapublicar tcm30-104720.pdf

${ }^{6}$ En 2014, el sector facturaron cerca de 848 Millones de euros en productos sanitarios y alimentación de animales de compañía, lo que supone un crecimiento del 8\% sobre el año anterior, según recoge el el citado Informe sobre el Análisis y la caracterización del sector de los animales de compañía 2015, p. 32. ${ }^{7}$ La petición de reforma del Código Civil español de la campaña \#AnimalesNOsonCosas ya supera, en la plataforma Change.org, las 300.000 firmas https://www.change.org/p/reforma-del-c\%C3\%B3digo- 
el hecho cierto e indubitado de que los animales no son cosas sino seres vivos dotados de sensibilidad de conformidad con el estado actual de la Ciencia ${ }^{8}$, lo que nos permite afirmar la sentiencia ${ }^{9}$ animal como una realidad científica irrefutable.

En efecto, en los últimos años los avances científicos han disipado muchos prejuicios sobre las capacidades de los animales, en concreto sobre cómo sienten o cómo se les puede incluso hacer merecedores de estatutos éticos que hasta hace relativamente poco estaban reservados a los humanos. Tal es el caso de los trabajos del eminente primatólogo Frans de Waal ${ }^{10}$, que sostienen que la empatía, la cooperación, la equidad y la reciprocidad son comportamientos morales no exclusivos de los seres humanos, tal y como se creía. En este sentido en 2012 se produjo un importantísimo progreso, cuando la comunidad científica reconoció, negro sobre blanco, en la llamada "Declaración de Cambridge sobre la Conciencia”, que no sólo los humanos tenemos conciencia ${ }^{11}$. Así, en una clara crítica a la todavía extendida noción cartesiana de que los animales no humanos son meras máquinas biológicas desprovistas de los sustratos neurológicos necesarios para poder atribuirles toda noción de conciencia ${ }^{12}$, un nutrido grupo de neurocientíficos de primer nivel afirmó, que los humanos no somos los únicos animales que poseemos esos sustratos neurológicos necesarios para tener conciencia.

Esta realidad ética, social y científica choca frontalmente con la legislación civil española, que se ha quedado anclada en la noción cartesiana de los demás animales como meras máquinas biológicas carentes de cualquier sensibilidad o inteligencia, dando la espalda a los avances éticos y científicos de los últimos siglos. Nuestro Código Civil de 1889 mantiene el estatuto jurídico del animal-cosa ${ }^{13}$, recibido en herencia de la Codificación napoleónica ${ }^{14}$. Y es que lo que en su momento pudo considerarse incluso como un avance ${ }^{15}$, es decir, que la regulación referente a los animales como bienes semovientes del sistema jurídico romano pudiera ser necesaria para reconocer a los animales "como realidad jurídica y como primer paso para entrar en la zona de protección del Derecho”, se ha convertido en el siglo XXI en un vestigio del pasado, que además choca desde 2009 con el mandato inequívoco introducido por el artículo 13 del Tratado de Funcionamiento de la Unión Europea (TFUE) ${ }^{16}$, que reconoce con pleno valor jurídico a los animales como seres

civil-espa\%C3\%B1ol-animalesnosoncosas

${ }^{8}$ Vid. Declaración de Cambridge de la Conciencia de 2012.

http://fcmconference.org/img/CambridgeDeclarationOnConsciousness.pdf y la posterior Declaración de Lisboa, que tuvo lugar el 8 de mayo de 2015 en el seno de la II International Conference of Alternatives to Animal Experimentation. http://infospedh.wixsite.com/spedh/declaration-of-lisbon

${ }^{9}$ GIMÉNEZ-CANDELA, T., La descosificación de los animales, Op. Cit., pp. 305-308.

${ }^{10}$ Vid. DE WAAL F. \& TYACK, P. (Eds.), Animal Social Complexity. Intelligence, Culture, and Individualized Societies, Harvard University Press, 2005 y DE WAAL F., La edad de la empatía. ¿Somos altruistas por naturaleza?, Tusquets, 2015.

${ }^{11}$ Vid. Declaración de Cambridge de la Conciencia de 2012 y la posterior Declaración de Lisboa, que tuvo lugar el 8 de mayo de 2015 en el seno de la II International Conference of Alternatives to Animal Experimentation. http://infospedh.wixsite.com/spedh/declaration-of-lisbon

${ }^{12}$ Cf. Vid. HENRIQUEZ, R., "La importancia de la distinción cartesiana entre el hombre y los animales", Ingenium. Revista de historia del pensamiento moderno, $\mathrm{N}^{\circ}$ 3, enero-junio, 2010, pp. 48-59

${ }^{13}$ MUÑOZ MACHADO, S. y otros, Los animales y el Derecho, Civitas, 1999, pp. 13-115.

${ }^{14}$ GIMÉNEZ-CANDELA, T., "Estatuto Jurídico de los animales: aspectos comparados”, en El Derecho de los Animales, Marcial Pons, Madrid, 2015, p. 149.

${ }^{15}$ Ibídem, p. 154.

${ }^{16}$ El artículo 13 TFUE, dispone. «Al formular y aplicar las políticas de la Unión en materia de agricultura, pesca, transporte, mercado interior, investigación y desarrollo tecnológico y espacio, la Unión y los Estados miembros tendrán plenamente en cuenta las exigencias en materia de bienestar de los animales como seres sensibles, respetando al mismo tiempo las disposiciones legales o administrativas y las costumbres de los Estados miembros relativas, en particular, a ritos religiosos, tradiciones culturales y patrimonio regional ». https://www.boe.es/doue/2010/083/Z00047-00199.pdf 
sintientes ${ }^{17}$.

España todavía no ha incorporado plenamente este reconocimiento de sentiencia animal en su corpus jurídico, en particular en el ámbito del derecho civil, como sí han hecho otros países del entorno europeo . Austria en 1988 fue el primer estado en acometer la reforma, estableciendo que los animales no son cosas y que están protegidos por las leyes. En segundo lugar Alemania acomete idéntica reforma en 1990, estableciendo también que los animales no son cosas y que están protegidos por leyes especiales y que sólo se les aplicarán las disposiciones de cosas con carácter supletorio en defecto de otras. En tercer lugar, Suiza en 2003, reforma su Código Civil con idéntica fórmula que los países precedentes.

Cataluña ${ }^{18}$ fue la primera Comunidad Autónoma española en actualizar el estatuto jurídico civil de los animales al reformar su Código Civil foral en 2006 especificando que los animales no son cosas.

Por su parte, Francia, si bien ya había reconocido desde 1976 a los animales como seres sensibles en su Código Rural y de Pesca Marítima, también reformó en 2015 su Código Civil para pasar a declarar expresamente que los animales son seres vivos dotados de sensibilidad. Y por último y más recientemente, nuestra vecina Portugal modificó en 2017 su código civil para también sacar del estatuto jurídico de las cosas a los animales y reconocerles como seres sensibles, entre otras medidas de protección.

Esta situación provoca que, por un lado, en nuestro país nos encontremos con la obligación legal de tener que aplicar un estatuto jurídico decimonónico a los animales, considerándolos como cosas, mientras que, por el otro, contrariamente la previsión del artículo 13 del TFUE obliga a los Estados miembros a reconocer a los animales como seres sentientes. Todo ello, en la práctica, como veremos, provoca no pocas disfuncionalidades, incoherencias y problemas aplicativos derivados del hecho de tener que aplicar una legislación del siglo XIX a la sociedad española del siglo XXI.

\section{LOS ANIMALES EN EL CÓDIGO CIVIL DE 1889}

Nuestro Código Civil decimonónico se refiere en numerosos preceptos a los animales ${ }^{19}$ no humanos. En este apartado haremos un breve recorrido por ese articulado, prestando atención a las disposiciones en las que aparezcan los animales.

Las primeras referencias y disposiciones que tienen relevancia para los animales en el Código Civil español las encontramos dentro del Libro Segundo, "De los bienes, propiedades y sus modificaciones":

En el artículo 333 se dispone que: "todas las cosas que son o pueden ser objeto de apropiación se consideran como bienes muebles o inmuebles”.

Referido a los bienes inmuebles, el artículo 334 reza lo siguiente: Son bienes inmuebles: " 6 o Los viveros de animales, palomares, colmenas, estanques de peces o criaderos análogos, cuando el propietario los haya colocado o los conserve con el propósito de mantenerlos unidos a la finca, y formando parte de ella de un modo permanente". De

\footnotetext{
${ }^{17}$ Adjetivo que describe la capacidad de sentir o sintiencia, según la Real Academia Española (RAE), en su Diccionario panhispánico de dudas de 2005, en castellano, puede traducirse por el adjetivo sentiente ('que siente'), forma que deriva directamente del latín sentiens, -entis (participio de presente de sentire) y que es la preferida en el uso culto. No obstante, la variación vocálica que el verbo sentir presenta en su raíz — sentimos, sintió — ha favorecido la creación de la variante sintiente, también válida. http://lema.rae.es/dpd/srv/search?key=sentir .

${ }^{18}$ Artículo 511-1.3 dispone expresamente que: "Los animales, que no se consideran cosas, están bajo la protección especial de las leyes. Solo se les aplican las reglas de los bienes en lo que permite su naturaleza”, introducido por la Ley 5/2006, de 10 de mayo, del libro quinto del Código Civil de Cataluña, relativo a los derechos reales.

${ }^{19}$ Vid. ROGEL, C., Los animales en el Código Civil, Reus, Madrid, 2017 y GIL, C., Régimen Jurídico civil de los animales de compañía, Dykinson, Madrid, 2014.
} 
conformidad con lo anterior, llama la atención que podrían conservar la consideración de bienes inmuebles (inmuebles por destino), los animales utilizados en criaderos ("criaderos análogos”) siempre que el propietario tenga el propósito de mantenerlos unidos al inmueble, en el que tenga lugar la actividad consistente en la explotación y cría de esos animales, de forma permanente.

Dentro de los bienes muebles, el artículo 335 establece lo siguiente: "Se reputan bienes muebles los susceptibles de apropiación no comprendidos en el capítulo anterior, y en general todos los que se pueden transportar de un punto a otro sin menoscabo de la cosa inmueble a que estuvieren unidos”. De conformidad con lo anterior, los animales tienen la consideración legal de bienes muebles semovientes, en tanto en cuanto, se pueden transportar de un punto a otro por virtud de un impulso que radica en el objeto mismo ${ }^{20}$.

Aclara el artículo 346 en su párrafo primero que "cuando por disposición de la ley, o por declaración individual, se use la expresión de cosas o bienes inmuebles, o de cosas o bienes muebles, se entenderán comprendidas en ella, respectivamente, los enumerados en el

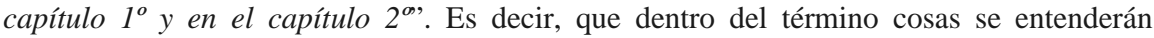
comprendidos tanto los bienes inmuebles, incluyendo también los animales considerados inmuebles por destino conforme al artículo $334.6^{\circ}$, como los bienes muebles semovientes, es decir, el resto de animales.

En el artículo 334 se dispone que los frutos de los bienes pertenecen al propietario y también en el primer párrafo del artículo 355 se hace mención a los productos derivados de los animales y a sus crías que son considerados frutos naturales ${ }^{21}$ : "son frutos naturales las producciones espontáneas de la tierra, y las crías y demás productos de los animales”.

En el mismo sentido el artículo 526 dispone, respecto al usufructo de rebaño o piara, que "el que tuviere el uso de un rebaño o piara de ganado, podrá aprovecharse de las crías, leche y lana en cuanto baste para su consumo y el de su familia, así como también del estiércol necesario para el abono de las tierras que cultive”.

Por su parte en el artículo 465, el Código Civil nos ofrece una suerte de clasificación de los animales en función de su carácter o docilidad para con el humano, claramente anticuada y no sujeta a rigor científico alguno ${ }^{22}$. En él se distingue entre los animales fieros, los domesticados o amansados y los mansos o domésticos ${ }^{23}$. El tenor literal del artículo 465 reza así: "Los animales fieros sólo se poseen mientras se hallen en nuestro poder; los domesticados o amansados se asimilan a los mansos o domésticos, si conservan la costumbre de volver a la casa del poseedor".

En este sentido conviene aclarar que lo que diferencia a los animales salvajes de los domésticos es que los primeros viven en libertad y no dependen del humano, al menos directamente, para subsistir, mientras que los segundos, producto de la domesticación, hace miles de años perdieron su condición de salvajes por entrar en contacto con el humano del que dependen para subsistir, y éste obtiene a cambio algún tipo de beneficio físico o inmaterial ${ }^{24}$.

Por tanto, dicha distinción no puede hacerse depender de la docilidad de carácter ni

\footnotetext{
${ }^{20}$ Véase MANRESA, J.M., Comentarios al Código Civil español, Reus, Madrid, 1934, Vol.3, p. 43.

${ }^{21}$ En este aspecto hay que reseñar que no se especifica a qué animales se refiere y si se trata de una actividad de cría de animales legal o de una clandestina y no sujeta a las normas actuales.

${ }^{22}$ La domesticación es un proceso estudiado por la Ciencia, especialmente por la Zooarqueología; Vid. BERNIS, F., Rutas de la Zooarqueología, Editorial Complutense de Madrid, 2001 y CLUTTONBROCK, J., A Natural History of domesticated mamals, Cambridge University Press, 1999.

${ }^{23}$ En este sentido, MANRESA, J. M., Op. Cit, Vol. 4, pp. 310-312, para quien el Código Civil sólo distingue 3 clases de animales: los domesticados para quienes remite a lo dicho para los bienes muebles, los animales fieros o salvajes o los amansados.

${ }^{24}$ En este concepto genérico de animal doméstico entrarían todos los animales de compañía, de granja, de renta o de producción, y también los animales salvajes en cautividad. Se entenderán, por tanto, animales de compañía sólo aquellos con los que convive el humano en su hogar por el mero disfrute de la compañía que le ofrecen estos animales.
} 
con ello va a variar la condición jurídica de una animal salvaje o doméstico, cuya condición y regulación debe ser de conformidad con las leyes especiales que les resulten de aplicación en cada caso ${ }^{25}$.

El Código Civil mantiene el llamado animus revertendi, o de consuetudo revertendi de los animales domésticos como requisito ${ }^{26}$ sine qua non para tener tal condición, de modo que parece deducirse erróneamente que si un animal doméstico no regresa, volvería ipso facto al estado salvaje, cuando lo que sucede es que, en virtud de las leyes autonómicas de protección animal vigentes en España y que operan como lex specialis y lex posterior, se convertirían legalmente en animales abandonados o errantes, bajo el amparo de las autoridades municipales y/o autonómicas, con las implicaciones legales que conlleva y que no les hace susceptibles de ser ocupados.

Además, la realidad simplificada y errónea que se desprende de la clasificación de los animales del artículo 465 no recoge la diversidad de posibilidades reales de coexistencia con el resto de animales que los humanos tenemos hoy en día, de modo, que se quedarían, por ejemplo, fuera de ella los animales salvajes en cautividad, los animales domésticos urbanos y periurbanos como las palomas o los animales exóticos que se mantienen artificialmente en muchos hogares como animales de compañía pero que si se dejasen al aire libre, no cumplirían el requisito del animus revertendi o costumbre de volver. Por tanto, parece claro que la complejidad que tiene la sociedad actual en relación a la tenencia de animales no está debidamente reflejada por Código Civil y por ello éste debe ser actualizado.

Respecto al usufructo se establece en el artículo $499^{27}$ que "si el usufructo se constituyere sobre un rebaño o piara de ganados, el usufructuario estará obligado a reemplazar con las crías las cabezas que mueran anual y ordinariamente, o falten por la rapacidad de animales dañinos. Si el ganado en que se constituyere el usufructo pereciese del todo, sin culpa del usufructuario, por efecto de un contagio u otro acontecimiento no común, el usufructuario cumplirá con entregar al dueño los despojos que se hubiesen salvado de esta desgracia. Si el rebaño pereciere en parte, también por un accidente, y sin culpa del usufructuario, continuará el usufructo en la parte que se conserve. Si el usufructo fuere de ganado estéril, se considerará, en cuanto a sus efectos, como si se hubiese constituido sobre cosa fungible".

En las disposiciones sobre las servidumbres relacionadas con los animales, el Código diferencia varios tipos de servidumbres.

En primer lugar, el artículo 553 en su párrafo primero establece una servidumbre de uso público respecto de las riberas de los ríos en interés de la pesca cuando dispone que "las riberas de los ríos, aun cuando sean de dominio privado, están sujetas en toda su extensión y sus márgenes, en una zona de tres metros, a la servidumbre de uso público en interés general de la navegación, la flotación, la pesca y el salvamento".

Otro grupo de servidumbres lo constituyen las relacionadas con usos ganaderos. Dentro de ellas se diferencian, de un lado, las que podríamos llamar como asistenciales: el abrevadero $^{28}$, el descansadero y la majada; y por otro lado, las servidumbres de paso para ganado o vías pecuarias ${ }^{29}$ : la cañada (anchura de 75 metros), el cordel (37 metros), la vereda

\footnotetext{
${ }^{25}$ En relación con los animales, tanto el Derecho Comunitario de la Unión Europea, como las leyes estatales de transposición y aquellas otras cuyo contenido sea de aplicación a los animales, así como las leyes autonómicas de protección animal, e incluso el propio Código Penal, prevalecen aplicativamente sobre los dispuesto en el Código Civil, por ser lex specialis y lex posterior que, además, debe ser interpretadas de conformidad con el artículo 13 del TFUE.

${ }^{26}$ MUÑOZ MACHADO, S. y otros, Op. Cit., p. 51.

${ }^{27}$ Llama la atención el lenguaje que utiliza el Código Civil y que hoy resulta claramente despectivo, al referirse a los animales como «animales dañinos » o el uso del término « despojos » para referirse a los animales enfermos o a sus cadáveres.

${ }^{28}$ En los artículos 555 y 556 se regula esta servidumbre como una servidumbre forzosa no en favor del predio sino en favor del ganadero necesitado de agua para dar de beber a sus animales.

${ }^{29} \mathrm{El}$ artículo 570 se refiere a las servidumbres de paso para el ganado. Las vías pecuarias se regulan por
} 
(20 metros) y el paso (10 metros).

Dentro de las servidumbres voluntarias, el Código Civil en los artículos 600-603, regula las comunidades y servidumbres de pastos.

Llegando ahora a los modos de adquirir la propiedad, nos encontramos con el controvertido tema de la ocupación en relación con los animales, el artículo 610, dispone lo siguiente: "Se adquieren por la ocupación los bienes apropiables por su naturaleza que carecen de dueño, como los animales que son objeto de la caza y pesca, el tesoro oculto y las cosas muebles abandonadas".

En este aspecto, nos encontramos con que cualquier animal que, de acuerdo con lo dispuesto en artículo 645, no conserve la costumbre de volver, se considerará res nullius y por tanto, será susceptible de ocupación ${ }^{30}$. Además, nos encontramos con en el supuesto de que animales domésticos ${ }^{31}$ (cosas muebles abandonadas), incluidos en ellos los de compañía, que si la conserven, si son abandonados deliberadamente por su propietario, también serán susceptibles de ser ocupados. Nuevamente nos encontramos con disposiciones totalmente contrarias a la legislación administrativa de protección animal vigente en nuestro país. Dicho esto, no podemos obviar que en el caso de los animales salvajes, tampoco se estaría hoy en día ante su posible consideración como res nullius, sino que no pueden ser apresados por nadie que no disponga de los permisos y las licencias necesarias conforme a la legislación especial de caza a la que remite el propio artículo $611^{32}$.

En el artículo 612 se dispone que:

"El propietario de un enjambre de abejas tendrá derecho a perseguirlo sobre el fundo ajeno, indemnizando al poseedor de éste el daño causado. Si estuviere cercado, necesitará el consentimiento del dueño para penetrar en él.

Cuando el propietario no haya perseguido, o cese de perseguir el enjambre dos días consecutivos, podrá el poseedor de la finca ocuparlo o retenerlo.

El propietario de animales amansados podrá también reclamarlos dentro de veinte días, a contar desde su ocupación por otro. Pasado este término, pertenecerán al que los haya cogido y conservado".

Respecto al derecho a perseguir el enjambre en fundo ajeno, cuya legalidad es puesta en cuestión por la doctrina en la actualidad ${ }^{33}$, deviene en una especie de ejercicio extrajudicial del propio derecho que no parece tener mucha virtualidad práctica en la sociedad actual.

Asimismo, dentro del término animales amansados que se utiliza en el tercer párrafo del artículo 612, recordemos que el criterio que utiliza el Código Civil para clasificar a los animales es el de la docilidad de carácter para con el humano, con independencia del origen del animal, de modo que dentro del término amansado podría estar cualquier animal manso y nuevamente este precepto no resulta aplicable a día de hoy, sin una remisión específica a la legislación especial.

A continuación el Código Civil establece unas reglas especiales sobre la ocupación de determinados animales ${ }^{34}$ que también resultan inaplicables a la luz de la anteriormente invocada legislación especial de protección animal (tanto respecto de animales domésticos

su legislación especial, principalmente por la Ley 3/1995, de 23 de marzo, de vías pecuarias.

${ }^{30}$ La ocupación es un modo originario de adquirir la propiedad de las cosas que o no son de nadie (res nullius) o han sido abandonadas por su dueño (res derelicta). Cfr. ROGEL, C., Op. Cit., p. 22.

31 A los que técnicamente considera res derelicta

${ }^{32}$ Respecto de los animales salvajes, fieros o fauna, el Código Civil sí que hace una remisión a las leyes especiales en el artículo 611. Remisión que no hace, en ningún caso, respecto del resto de animales, a pesar de que existe una profusa legislación especial en nuestro país que regula tanto las condiciones de bienestar animal de los animales domésticos de granja como las condiciones de tenencia y protección de los animales de compañía.

${ }^{33}$ DÍEZ-PICAZO, L., Fundamentos del Derecho Civil Patrimonial. Vol. VI. Derechos reales, Civitas,Thomson Reuters, 2012. p. 47.

${ }^{34}$ Se refiere a las denominadas formas de colombicultura, cunicultura y la piscicultura. 
en general como de animales de compañía). En este sentido, en el artículo 613 se establece que "las palomas, conejos y peces, que de su respectivo criadero pasaren a otro perteneciente a distinto dueño, serán propiedad de éste, siempre que no hayan sido atraídos por medio de algún artificio o fraude".

En el artículo 615 se regula el hallazgo de cosa mueble, entre los que están, como sabemos, los animales por cuanto son considerados semovientes. El propio artículo obliga, pasado el tiempo, incluso a vender a los animales encontrados en pública subasta, lo cual, es simplemente inviable hoy en día y, en el caso de los animales de compañía, claramente contrario a la legislación especial que establece cómo se ha de proceder en caso de encontrarse un animal abandonado o errante. También en este aspecto, ofrece el Código una regulación a todas luces anticuada y que hace necesaria nuevamente la remisión normativa a la profusa legislación administrativa especial, europea, estatal y autonómica, que regula aspectos relacionados con las condiciones de vida, explotación, transporte, tenencia y protección de los animales.

Otro aspecto relevante en relación con los animales es el referido a la venta de animales, y en concreto a la regulación de los vicios ocultos de los animales vendidos y el saneamiento. No olvidemos que cualquier animal, en cuanto cosa mueble, es susceptible de ser vendido, máxime cuando en nuestro país todavía no existe una regulación nacional que prohíba o limite su venta ${ }^{35} \mathrm{y}$, por tanto, los animales no son considerados res extra commercium $^{36}$, por lo que se les aplican las disposiciones del Código Civil sobre compraventa, sin que nuevamente se haga una remisión normativa a la legislación especial sobre la venta de animales contenida en las leyes administrativas autonómicas de protección animal o en las ordenanzas municipales de tenencia responsable y protección animal.

Entre los artículos 1491 y 1499, el Código Civil contiene una serie de reglas especiales en relación con la venta de animales que penetraron en nuestro sistema legal tomadas del Edicto de los Ediles ${ }^{37}$ respecto de los esclavos y las "bestias de carga" y han permanecido hasta nuestros días. Por supuesto en aquella época no era común la actual consideración de los animales de compañía pero estas disposiciones les son, todavía, plenamente aplicables.

En los artículos 1494 y 1495 se regulan los llamados vicios o defectos ocultos, que en el caso de la venta de animales vendrán a ser las enfermedades o la "inutilidad de su uso". Huelga decir que en ninguno de estos aspectos se tiene en cuenta ni el bienestar del animal, ni el tratamiento veterinario de la enfermedad del animal, ni sus intereses más básicos, ni el vínculo de afectividad o el apego que pueda sentir el comprador hacia el animal "viciado". Dice así el artículo 1494: "No serán objeto del contrato de venta los ganados y animales que padezcan enfermedades contagiosas. Cualquier contrato que se hiciere respecto de ellos será nulo. También será nulo el contrato de venta de los ganados y animales, si, expresándose en el mismo contrato el servicio o uso para que se adquieren, resultaren inútiles para prestarlo".

Por su parte el artículo 1495 decreta que "cuando el vicio oculto de los animales, aunque se haya practicado reconocimiento facultativo, sea de tal naturaleza que no basten los conocimientos periciales para su descubrimiento, se reputará redhibitorio. Pero si el profesor, por ignorancia o mala fe, dejara de descubrirlo o manifestarlo, será responsable de los daños y perjuicios".

\footnotetext{
${ }^{35}$ Lamentablemente no salió adelante la necesaria regulación de la cría y venta de animales de compañía en nuestro país y nunca llegó a tramitarse el Anteproyecto de Ley por el que establece la normativa básica del comercio y tenencia responsable de perro y gatos. http://www.rsce.es/web/images/rsce/noticias/BorradorAPL_comercio tenencia responsable_perrosgatos.pdf

${ }^{36}$ En el Derecho Romano eran las cosas que se hallaban fuera del comercio y respecto de las cuales no era posible el denominado ius commercii. En consecuencia, no podían ser objeto de adquisición ni de actos patrimoniales entre vivos o por causa de muerte.

${ }^{37}$ Cfr. ROGEL, C., Op. Cit., p. 59.
} 
En el artículo 1496 se estipula que "la acción redhibitoria que se funde en los vicios o defectos de los animales, deberá interponerse dentro de cuarenta días, contados desde el de su entrega al comprador, salvo que, por el uso en cada localidad, se hallen establecidos mayores o menores plazos. Esta acción en las ventas de animales sólo se podrá ejercitar respecto de los vicios y defectos de los mismos que están determinados por la ley o por los usos locales".

Por su parte el artículo 1497 añade que "si el animal muriese a los tres días de comprado, será responsable el vendedor, siempre que la enfermedad que ocasionó la muerte existiera antes del contrato, a juicio de los facultativos".

En el artículo 1498 se establece que "resuelta la venta, el animal deberá ser devuelto en el estado en que fue vendido y entregado, siendo responsable el comprador de cualquier deterioro debido a su negligencia, y que no proceda del vicio o defecto redhibitorio”.

Finaliza el tema de las ventas de animales el artículo 1499 disponiendo que "en las ventas de animales y ganados con vicios redhibitorios, gozará también el comprador de la facultad expresada en el artículo 1.486; pero deberá usar de ella dentro del mismo término que para el ejercicio de la acción redhibitoria queda, respectivamente, señalado”.

Esta cosificación de los animales en nuestra legislación civil no refleja ni hace, por cuanto que es muy anterior, ninguna remisión o referencia al bienestar animal. En este sentido conviene recordar que España forma parte de la OIE (Organización Mundial de Sanidad Animal) y de este organismo internacional emanan normas aplicables en nuestro país y que en esta materia también son legislación especial. En concreto es necesario hacer mención a lo dispuesto en el artículo 7.1.2 de su Código Sanitario para los Animales Terrestres ${ }^{38}$, en el que se alude a la obligación de que a los animales les mantenga respetando sus necesidades más básicas o también conocidas como las 5 libertades del bienestar animal:

- Libres de sed y el hambre: libre acceso a agua fresca y a recibir una dieta suficiente y adecuada para mantener la salud y la vitalidad según la especie.

- Libres de incomodidad: proporcionándoles un entorno adecuado, incluyendo refugio y una zona de descanso confortable acorde con las necesidades propias de cada especie.

- Libres de dolor, lesiones y enfermedades: mediante la prevención o el diagnóstico y tratamiento veterinario rápido.

- Libres de expresar un comportamiento normal y natural para la su especie: al proporcionarles un espacio suficiente, instalaciones adecuadas y la posibilidad de comportarse conforme a las necesidades etológicas propias de cada especie.

- Libres de miedo y angustia: respecto al trato recibido y a las condiciones de vida y tenencia por parte de su responsable.

En otro orden de cosas, siempre teniendo en cuenta que lo contenido en la legislación civil respecto a los bienes muebles (y a los inmuebles por destino) puede ser aplicable todavía hoy a los animales, el Código Civil contiene normas relativas a los arrendamientos de animales en el marco de las Disposiciones especiales para los arrendamientos de predios rústicos.

En el artículo 1575, y teniendo en cuenta que, como hemos visto anteriormente, las crías de los animales se consideran frutos naturales, se dispone que "el arrendatario no tendrá derecho a rebaja de la renta por esterilidad de la tierra arrendada o por pérdida de frutos provenientes de casos fortuitos ordinarios; pero sí, en caso de pérdida de más de la mitad de frutos por casos fortuitos extraordinarios e imprevistos, salvo siempre el pacto especial en contrario. Entiéndese por casos fortuitos extraordinarios: el incendio, guerra,

38 Código Sanitario para los Animales Terrestres OIE, http://www.oie.int/es/normas/codigoterrestre/acceso-en-linea/ 
peste, inundación insólita, langosta, terremoto u otro igualmente desacostumbrado, y que los contratantes no hayan podido racionalmente prever".

Respecto al arrendamiento por aparcería de ganado de cría, se decreta en el artículo 1579 que "el arrendamiento por aparcería de tierras de labor, ganados de cría o establecimientos fabriles e industriales, se regirá por las disposiciones relativas al contrato de sociedad y por las estipulaciones de las partes, $y$, en su defecto, por la costumbre de la tierra" 39 .

Se finaliza este recorrido por el articulado del Código Civil de 1889 referente a los animales haciendo mención a lo promulgado, por un lado, respecto a las carreras de animales, y por otro a los daños provocados por los animales y la responsabilidad civil extracontractual.

Dejando nuevamente clara la necesidad de que la legislación civil sea actualizada y, sin hacer mención a la legislación especial ${ }^{40}$, el artículo 1800 establece que "no se consideran prohibidos los juegos que contribuyen al ejercicio del cuerpo, como son los que tienen por objeto adiestrarse en el manejo de las armas, las carreras a pie o a caballo, las de carros, el juego de pelota y otros de análoga naturaleza”.

En relación con la responsabilidad civil por los daños ocasionados por animales, el Código Civil establece en los artículos 1905 y 1906 unas reglas especiales, al margen de la responsabilidad por culpa del 1902, referidas a los daños ocasionados por animales en dos escenarios diferenciados.

Por un lado, el artículo 1905 manifiesta, respecto de cualquier animal, que "el poseedor de un animal, o el que se sirve de él, es responsable de los perjuicios que causare, aunque se le escape o extravíe. Sólo cesará esta responsabilidad en el caso de que el daño proviniera de fuerza mayor o de culpa del que lo hubiese sufrido".

Por otro lado, el artículo 1906 dispone que "el propietario de una heredad de caza responderá del daño causado por ésta en las fincas vecinas, cuando no haya hecho lo necesario para impedir su multiplicación o cuando haya dificultado la acción de los dueños de dichas fincas para perseguirla".

Finalizamos este apartado, observando que nada dice el Código Civil respecto de la responsabilidad civil por daños causados a los propios animales ${ }^{41}$, situación ésta que lleva a tener que aplicar analógicamente todo lo dispuesto respecto a la responsabilidad civil contractual y extracontractual, dependiendo del supuesto de que se trate. Respecto a la responsabilidad civil de veterinarios y clínicas veterinarias es común hoy en día la aplicación analógica de lo dispuesto jurisprudencial y doctrinalmente para las negligencias médicas, incluyéndose en las partidas indemnizatorias, en muchos casos, la de los daños morales respecto de animales en los que ha quedado acreditado el lazo de afectividad existente entre el animal y la persona que lo cuida. Hecho este que debería servir para reforzar la necesidad de revisar la regulación decimonónica que sigue ofreciendo el Código Civil al referirse a los demás animales.

\section{PROBLEMAS PRÁCTICOS Y NECESIDAD DE LA ACTUALIZACIÓN}

La superación de este anacrónico estatuto jurídico del animal como cosa, si se logra llevar a cabo a través de la reforma legal propuesta, podría no ya solo adecuarnos al sentir social, ético y jurídico anteriormente referido, sino que pondría solución a no pocos problemas que surgen en la resolución cotidiana de conflictos privados que tienen que

\footnotetext{
${ }^{39}$ Respecto a lo estipulado en este precepto la doctrina lo considera confuso y no queda claro si en realidad ese trata de un arrendamiento por cría de ganado o de una aparcería pecuaria. En cualquier caso queda de manifiesto el marcado carácter agrícola de la sociedad de la época a la que se dirigía que como sabemos era eminentemente agrícola. Véase ROGEL, C., Op. Cit., pp. 72-75.

${ }^{40}$ Leyes del juego estatales y autonómicas en vigor actualmente.

${ }^{41}$ No son pocos los casos en la casuística judicial actual en los que se reclaman indemnizaciones por los daños ocasionados a animales en el ejercicio de determinados servicios prestados a los animales como los servicios veterinarios, peluquería, adiestramiento, guardería, etc.
} 
dirimirse con una legislación claramente desfasada.

Con la actualización del estatuto jurídico civil de los animales y el abandono del paradigma de tradición romana del animal-cosa se ganaría en seguridad jurídica y se dotaría de coherencia interna al Ordenamiento Jurídico español. Además, debemos tener en consideración, en primer lugar, que nuestro Código Civil también debe adecuarse al principio constitucional establecido desde 2009 en el artículo 13 del TFUE, que reconoce a los animales como seres sintientes o sensibles. En segundo lugar, existe la necesidad extender al Derecho Civil los principios y mandatos de protección animal que ya operan como ley especial y posterior, y que progresivamente han ido surgiendo y desarrollándose en otros sectores del Derecho, como por ejemplo en el Derecho Internacional y Comunitario Europeo, o en el Derecho sancionador de protección animal, tanto Administrativo como Penal.

En el ámbito del Derecho Penal, España ha avanzado especialmente en los últimos años respecto a la protección de los animales. Nuestro Código Penal ${ }^{42}$ tipifica como delito el maltrato animal desde 2004, y esta protección se ha visto reforzada gracias a la más reciente reforma legal, que entró en vigor el pasado 1 de julio de 2015.

No podemos perder de vista que las situaciones en las que los tribunales están llamados a aplicar esta arcaica legislación civil en relación con los animales y, a resolver los conflictos asociados a su tenencia, abarcan multitud de supuestos. No olvidemos que al tratarse de una legislación decimonónica, en ella no sólo no se tiene en cuenta el interés del animal ni su bienestar, sino que tampoco se da respuesta a multitud de supuestos de hecho comunes a día de hoy. Y las respuestas que se pueden dar entran en contradicción, en no pocos casos, con otros sectores del ordenamiento que, como hemos visto, no sólo operan como ley posterior sino también como ley especial. Recordemos, por ejemplo, que para el vigente Código Civil, los animales son bienes muebles, semovientes, que pueden ser objeto de apropiación conforme a lo dispuesto en los artículos 610 y siguientes del CC. Teniendo en cuenta la época en la que fueron redactados sus preceptos, no es de extrañar tampoco que nuestro Código Civil disponga, en relación con los animales domésticos o amansados, que si no tienen la costumbre de regresar (consuetudo revertendi), es decir, puedan ser objeto de apropiación mediante la ocupación como forma de adquirir la propiedad y que puedan ser considerados res nullius, o que se les aplique lo dispuesto artículo 615 para el hallazgo.

Este estatuto jurídico-civil del animal-cosa entra en muchos casos en contradicción con las leyes autonómicas de protección animal o incluso con el propio Código Penal, leyes ambas que prevalecen aplicativamente como lex specialis y lex posterior sobre el Código Civil, que además, recordemos, debe ser interpretado conforme el artículo 13 TFUE. Así, por ejemplo, de las 17 leyes autonómicas de protección animal vigentes en nuestro país se deriva mutatis mutandis que los animales domésticos que no tienen dueño conocido, animales a los que se les denomina abandonados o errantes, están bajo el amparo y responsabilidad exclusiva de las Administraciones Locales o Autonómicas, que son quienes tienen el deber legal de ampararlos y conducirlos a los centros de acogida de animales creados al efecto para que, pasados los plazos legales establecidos, puedan, en el mejor de los casos, ser reclamados por sus responsables o ser dados en adopción. Además, respecto a los animales "fieros", que es como se refiere nuestro Código Civil a los animales salvajes, si bien existe una remisión a la legislación especial de caza y pesca en el artículo 611, debiera existir una remisión normativa a la tutela penal de los salvajes del Código Penal frente al furtivismo, y que haría depurar responsabilidades incluso penales por la indebida captura de un animal salvaje.

Nos centraremos a continuación en los aspectos civiles en los que vemos que existe reiterada jurisprudencia en la que queda de manifiesto que nuestro Código Civil debe ser reformado para dar una respuesta actualizada y útil a los supuestos de hecho actuales.

Empezaremos por analizar algunas de las principales materias dentro del ámbito del

\footnotetext{
${ }^{42}$ MENÉNDEZ DE LLANO, N., "La protección penal de los animales tras la reforma de 2015", Law\&Trends, 27 de diciembre de 2016. http://www.lawandtrends.com/noticias/penal/la-proteccionpenal-de-los-animales-tras-la.html
} 
Derecho Civil donde nuestros tribunales tienen que dar respuesta a problemas actuales aplicando un Código Civil del siglo XIX.

En primer lugar nos detendremos en los contratos de transporte privado de animales que, aunque mayoritariamente considerados de carácter mercantil, tienen, además de en las Leyes especiales, en el Código Civil -por expresa remisión normativa del art. 50 del Código de Comercio- su base normativa general en materia contractual. En este campo, podemos aseverar que no son pocos los conflictos derivados del hecho de que en muchos medios de transporte de pasajeros, tanto terrestre, como marítimo o aéreo, se sigue tratando a los animales como mercancías, obligando a sus responsables a introducirlos en las bodegas o maleteros que no están debidamente acondicionados y resultan peligrosos para la integridad y la vida de los animales, todo ello, puede ser además contrario a lo dispuesto en la legislación especial, concretamente a la obligación comúnmente aceptada en las legislaciones autonómicas de protección animal, de tratar adecuadamente al animal de manera que no se le provoque sufrimiento o se ponga en riesgo su vida.

Que los animales sean, legalmente tratados como objetos, bultos o mercancías, en la práctica, se traduce en que muchos de ellos llegan muertos, gravemente enfermos, o en otros muchos casos las jaulas o trasportines en los que viajan, están tan dañados que el animal se pierde al ser abiertas las compuertas de la aeronave o embarcación. Son multitud las reclamaciones extrajudiciales y pleitos civiles y mercantiles que cada año se suceden en nuestro país por este motivo. Razón que, además, dificulta el traslado de los animales de compañía en los periodos vacacionales y que no ayuda precisamente a prevenir y luchar contra el abandono de animales que, como sabemos, es un grave problema en España.

Entre otras muchas, destaca la sentencia de la Audiencia Provincial de Islas Baleares (Sección 5a) núm. 180/2009 de 25 de mayo de 2009 referida al servicio de transporte de un perro que murió durante el mismo por un golpe de calor al viajar como un bulto sin condiciones para poder soportar ese viaje. Por su parte, la sentencia de la Audiencia Provincial de Madrid (Sección 25a) núm. 240/2008 de 13 de mayo de 2018, condena a indemnizar la muerte de un perro transportado en una furgoneta y que también muere por golpe de calor. La sentencia de la Audiencia Provincial de Málaga (Sección $4^{\mathrm{a}}$ ) núm. 142/2007 de 14 de marzo de 2007, condena también a una compañía aérea a indemnizar a la actora que embarcó a su perro en un vuelo con origen Buenos Aires y destino Málaga, llegando el trasportín roto y vacío por haberse extraviado el perro durante el viaje por negligencia de la compañía, por caída y rotura del trasportín durante la carga y descarga del equipaje.

Por desgracia, también el ámbito del transporte, son frecuentes las reclamaciones de asegurados que tras tener un percance o avería en carretera y solicitar a su entidad aseguradora la asistencia de un transporte auxiliar, se niegan a hacerse cargo del transporte de sus animales quedando en una situación de desamparo. O aquellos otros en los que los ocupantes de un vehículo siniestrado son asistidos por los servicios de emergencia, mientras que los animales que viajaban en el mismo vehículo no reciben ningún tipo de asistencia.

Lamentablemente parece claro que si la legislación civil no tiene en cuenta la sentiencia de los animales como seres vivos no podemos esperar que los resultados de su aplicación en los contratos mercantiles de transporte sean diferentes.

En segundo lugar, otro bloque material importante de supuestos que generan multitud de reclamaciones extrajudiciales y judiciales se derivan de la compraventa de animales de compañía por estar los animales enfermos. En esas situaciones la práctica comercial habitual suele ser la de ofrecer automáticamente el cambio del cachorro enfermo por otro sano, tratándolo como una simple mercancía y sin tener en cuenta el afecto que ya se tiene hacia el animal.

En estos casos, sale más rentable la permuta del animal enfermo por otro sano que hacer frente a los gastos veterinarios para curar y salvar la vida del cachorro enfermo. Por esta razón, algunos tribunales, con buen criterio, para evitar la aplicación del obsoleto estatuto del animal-cosa, han tenido que recurrir en sus resoluciones judiciales a considerar 
al animal como un "bien de carácter especial” o declarar la insustituibilidad del animal, en caso de saneamiento por vicios ocultos o incumplimientos contractuales.

En este sentido es especialmente elocuente la sentencia de la Audiencia Provincial de Girona, de 30 de junio de 2011, en la que se hace referencia al carácter especial de los animales objeto de venta y cómo se ha de tener en cuenta su insustituibilidad en caso de reemplazo del animal por otro, atendiendo al afecto que se le haya cogido, ya que su obtención no persigue una mera necesidad material, obligando al sacrificio del animal si el enfermo es sustituido por otro que sea dado en su lugar al comprador. También resulta elocuente lo dispuesto en la sentencia de la Audiencia Provincial de Granada, de 21 de noviembre de 2008, que reconoce que "la disconformidad de la compradora se debe a que el perro fue entregado, según alegaciones suyas en la demanda de juicio verbal, en unas condiciones deplorables-delgadez, vientre abultado, heces de consistencia blanda, con una fuerte anemia, infecciones- que hizo que necesaria la intervención de un veterinario al día siguiente de su entrega. Según la actora, hubo con anterioridad conversaciones con la empresa vendedora, sin que hubiera una solución. Lo cierto es que el perro padecía estas anomalías y enfermedades antes de la entrega. Como es lógico, a la compradora no le quedó más remedio que acudir a un veterinario para ayudar así al pobre perro".

En tercer lugar, se constata igualmente que son múltiples los conflictos que surgen en el reparto de la tenencia de un animal de compañía entre los miembros de la pareja ante el sobrevenimiento de las crisis familiares.

Cada vez resulta más frecuente que en los propios convenios reguladores se incluyan medidas relativas a los animales de compañía. Es reseñable cómo los propios tribunales, entienden que, cuando un animal pertenece pro indiviso a varios miembros de la familia, al tratarse de un bien indivisible, ha de arbitrarse un sistema adecuado a su naturaleza indivisible. En este sentido son interesantes la sentencia de la Audiencia Provincial de Barcelona, de 5 de abril de 2006 y la sentencia de la Audiencia Provincial de León de 25 de noviembre de 2011. En esta última puede leerse que "no resulta extraño que en convenios reguladores de la separación, el divorcio y sus efectos, se contemplen disposiciones para regular la posesión de las mascotas porque es evidente el cariño y afecto que surge por estos animales entre quienes les han cuidado, estableciendo en ocasiones derecho de utilización alterna y otras medidas que favorecen el cuidado por ambos propietarios”.

Además, hay que resaltar que no resulta pacífica la solución a las dificultades que surgen en esta materia, por ejemplo en el supuesto de solicitud de un régimen de visitas en relación a un animal de compañía en un procedimiento de separación, y si podría o no solicitarse la ejecución posterior dentro del propio procedimiento de familia. Contrario a ello ha resultado el criterio de la Audiencia Provincial de la Coruña en sentencia de 6 de abril de 2006, al considerar que esta cuestión debe dilucidarse en fase de ejecución referido a la mera adjudicación de semoviente.

No obstante lo anterior, la mayoría de las parejas se encuentran con el problema una vez que sucede la ruptura o la separación. En estas situaciones no son pocos los casos en los que se solicita por alguna de las partes o por ambas la adjudicación del animal, por cuanto se trata legalmente de un bien, o diversamente la custodia privativa o compartida del animal o un régimen de visitas, asemejando el lenguaje jurídico al de la custodia de los menores.

La jurisprudencia es muy dispar, teniendo en cuenta que con la legislación actual resulta difícil que el juzgador tenga en cuenta el bienestar del animal y no se limite exclusivamente a verificar quién resulte ser su legítimo propietario y quién de los dos va a seguir disfrutando de la posesión de ese singular bien mueble al que unen profundos lazos afectivos y que tiene sus propios intereses y necesidades. Resultan ilustradoras de esta disparidad de criterio a la hora de valorar si las indemnizaciones, por los daños que ha sufrido un animal deben cubrir o no los daños morales, las sentencias del Juzgado de Primera Instancia $^{\circ} 40$ de Madrid, de 12 de marzo de 2016, y la del Juzgado de Primera Instancia ${ }^{\circ}$ 2 de Badajoz, de 7 de noviembre de 2010.

En tercer lugar, debe tratarse un tema importante teniendo en cuenta los millones de 
animales de compañía que esperan en nuestro país en albergues, refugios y perreras una oportunidad para ser adoptados. Lo que comúnmente es conocido como el contrato (verbal o escrito) de adopción de un animal de compañía es fuente de multitud de conflictos, tanto respecto a la interpretación de la propia naturaleza de tal contrato ${ }^{43}$, como respecto a su incumplimiento. Con razón los juzgadores no se ponen de acuerdo a la hora de interpretar la naturaleza jurídica de estos contratos que regulan estas adopciones con independencia del nomen iuris (adopción, acogimiento, casa de acogida, etc.) que reciban. Algunos juzgadores asemejan el contrato de adopción de animales a una donación modal, a un contrato de depósito, a un usufructo o incluso a una compraventa. Tampoco se ponen de acuerdo en las soluciones que dan en sus resoluciones judiciales ante los conflictos que surgen, tal y como queda patente, entre otras, en la sentencia de la Audiencia Provincial de La Coruña, de 6 de abril de 2006 y en la sentencia del Juzgado de Primera Instancia $n^{0} 1$ de Ferrol, de 1 de diciembre de 2010.

En cuarto lugar, otra frecuente fuente de litigios civiles con animales implicados que pone de relieve el anacrónico estatuto jurídico civil de éstos es la relativa a las relaciones de vecindad. Es tristemente habitual que en la práctica se esté considerando la tenencia de animales dentro del régimen de Propiedad Horizontal como una actividad prohibida, molesta o insalubre. De hecho, en base a esta consideración, recogen en sus Estatutos y normas de régimen interno la prohibición a limine de tener animales de compañía, sin ninguna molestia previa concreta que lo justifique.

Esta situación jurídica además de ser de dudosa legalidad ${ }^{44}$, pone nuevamente a los animales en una situación de vulnerabilidad y desamparo que no en pocas ocasiones es la razón de múltiples abandonos de animales de compañía y de verdaderos dramas familiares, al verse forzados a desprenderse del animal, ya que no todo el mundo tiene los medios ni la formación para defender judicialmente, si llega el caso, la posibilidad de mantener la tenencia del animal.

Es cierto que el prejuicio de que la tenencia de animales de compañía va asociada a suciedad y molestias vecinales tiene su origen en una mala fama fruto de la irresponsable tenencia de animales por parte de algunas personas (molestias derivadas de animales que son dejados solos durante muchas horas sin atención, ladridos, excrementos en zonas comunes, malos olores, etc.). Pero solo en el caso de esas personas irresponsables tienen sentido las citadas prohibiciones, es decir, deben ser prohibiciones por molestias ad casum y no prohibiciones generales y apriorísticas.

No obstante, para que el juzgador pueda tener en cuenta el interés del animal como ser vivo sintiente y no como un mero bien mueble al resolverlo el litigio, en caso de que el conflicto vecinal se judicialice, el estatuto de los animales en el Código Civil debería estar debidamente actualizado.

Resultan ilustradoras de las habituales prohibiciones generales de tenencia de animales sin que se hubiere acreditado ninguna molestia previa ad casum, las sentencias del Tribunal Supremo de 11 de octubre de 1978 y de 14 de noviembre de 1984; así como las sentencias de la Audiencia Provincial de Asturias de 21 de julio de 1999, de la Audiencia

\footnotetext{
43 Existen multitud de dudas doctrinales y jurisprudenciales sobre la naturaleza jurídica de los llamados contratos de adopción de animales de compañía. No queda claro si se trata de un tipo de donación modal, de cesión del uso en precario, de depósito o si se trata de unos contratos atípicos diferentes. Véase GIL MEMBRADO, C., Régimen Jurídico Civil de los animales de compañía, Dykinson, Madrid, 2014, pp.72-80.

${ }_{44}$ Tal y como ya se ha tratado la cuestión la ilegalidad de las prohibiciones generales por tenencia de animales de compañía en el régimen de Propiedad Horizontal, en MENÉNDEZ DE LLANO, N., «Animales y conflictos vecinales: ¿pueden mis vecinos prohibirme tener animales? », Law\&Trends, 7 de febrero de 2017. http://www.lawandtrends.com/noticias/civil/animales-y-conflictos-vecinalespueden-mis.html
} 
Provincial de Guipúzcoa de 15 de mayo de 2009 y de la Audiencia Provincial de Madrid de 16 de marzo de 2011.

En quinto lugar y último lugar, consideraremos otro sector en el que existe numerosa casuística relativa a las reclamaciones por responsabilidad civil, derivada tanto de la negligencia profesional e intrusismo profesional en la que los animales son las víctimas de la mala praxis, como de los daños ocasionados por animales a otros animales, bienes o personas.

Teniendo en cuenta que la sociedad actual nada tiene que ver con la sociedad de 1889, como consecuencia de los millones de animales que conviven con nosotros en los hogares españoles, ha habido un prominente desarrollo de actividades profesionales que ofertan servicios dirigidos a los animales como, por ejemplo, servicios veterinarios, peluquería, residencias para animales, adiestramiento, paseadores, etc.

En estos casos, con independencia de que los daños los haya causado un profesional o un estafador y, al margen de que la responsabilidad civil exigida sea contractual o extracontractual, se hace nuevamente necesaria la reforma del estatuto jurídico civil de los animales, toda vez que no hay un único criterio judicial a la hora de valorar los daños materiales causados a los animales, ni tampoco para la estimación de los daños morales. Para que el quantum indemnizatorio, no quede claramente limitado a los daños materiales o al valor probado del animal, éste debe dejar de ser considerado como un mero objeto.

Sobre esta cuestión es evidente que el criterio del juzgador varía en función de su propia sensibilidad hacia los animales, sin que la legislación actual ofrezca un criterio unificador que permita tener en cuenta al animal como ser vivo con capacidad de sentir y protegido por las leyes especiales y no como un mero objeto en propiedad. En este sentido, merecen mención las sentencias de la Audiencia Provincial de Málaga, de 25 de febrero de 2008; de la Audiencia Provincial de Madrid, de 23 de diciembre de 2014; de la Audiencia Provincial de Valencia, de 14 de octubre de 2009; de la Audiencia Provincial de Barcelona, de 4 de mayo de 2011 y de la Audiencia Provincial de Sevilla, de 12 de mayo de 2008.

Para finalizar, se ha de hacer una somera mención al creciente número de reclamaciones derivadas de las coberturas de los distintos seguros relacionados con los animales de compañía. No en vano se ha generalizado en España la existencia de estos seguros para animales de compañía ${ }^{45}$. Los seguros de responsabilidad de civil tienen el carácter obligatorio ex lege para la tenencia de los legalmente considerados animales potencialmente peligrosos ${ }^{46}$. Pero, además de éstos, existe un amplio número de seguros en nuestro país dirigidos a los animales de compañía que junto con la responsabilidad civil voluntaria también ofrecen cobertura sanitaria veterinaria, en caso de accidentes, defensa legal, reclamación de daños, eutanasia, gastos de incineración, etc. Se hace necesaria la reforma para que se tenga en cuenta también el interés del animal en la resolución de posibles conflictos privados que puedan surgir en estas materias.

En vista de todo lo anteriormente expuesto, es de esperar que el legislador español modernice cuanto antes el estatuto jurídico civil de los animales y deje de considerarlos cosas. De este modo no solo se adecuaría al reconocimiento científico, ético, social y legal de los animales como seres sintientes que ya impone el Derecho Originario de la Unión Europea, sino que, además, se alinearía con los más avanzados Estados de nuestro entorno. Con ello ganaríamos una legislación civil acorde al tiempo en el que tiene que ser aplicada,

\footnotetext{
${ }^{45}$ Véase RODRÍGUEZ, E./GRANADOS, M., Seguro animal, ¿¿animal seguro ?, TFG de la Facultad de Veterinaria, Universidad Autónoma de Barcelona, 2011. https://ddd.uab.cat/pub/trerecpro/2011/80077/seguro animal_animal seguro.pdf

${ }^{46}$ Ley 50/1999, de 23 de diciembre, sobre el Régimen Jurídico de la Tenencia de Animales Potencialmente Peligrosos y Real Decreto 287/2002, de 22 de marzo, por el que se desarrolla la anterior ley. Ambas normas se aplicarán supletoriamente en el caso de que exista legislación autonómicamente en la materia y serán de plena aplicación en aquellas Comunidades Autónomas en las que se carezca de legislación autonómica en esta materia.
} 
ofreciendo a los operadores jurídicos, y muy especialmente a los aplicadores del Derecho, una herramienta útil basada en un criterio congruente para resolver los conflictos que, como hemos visto, se dan en el día a día judicial, y que por el momento obligan a los tribunales a tener que aplicar una legislación anticuada y muy alejada del sentir social actual por no contemplar los intereses más básicos de los animales. 